\title{
Nesne Tabanlı Sınıflandırma ile Taşkın Alanlarının Analizi
}

\author{
Abdurahman Yasin YíğiT ${ }^{1 *}$ ve Murat UYSAL ${ }^{1}$
}

\section{Öz}

Modern uzaktan algılama (UA) sistemleri, dünyadaki hemen hemen tüm disiplinler tarafından yaygın olarak kullanılmaktadır ve kapsamları gün geçtikçe artmaktadır. Günümüzde, uydulardan elde edilen uzaktan algılama verilerini bilgisayar teknolojisi ve görüntü işleme teknikleri ile değerlendirme imkânı; mevcut arazi kullanımının belirlenmesi ve çevresel değişimlerin geçici olarak belirlenmesi ile mümkün olmuştur. Uzaktan algılama teknikleriyle arazi örtüsü haritaları oluşturmanın temel prensibi alanın görüntülerini sınıflandırmaktır. Arazideki zamana bağlı değişimler, uydulardan elde edilen uzaktan algılama verilerinin işlenmesi ve sınıflandırılmasıyla tespit edilebilir. Deprem olaylarının, sellerin, yangınların, toprak kaymalarının ve çığların meydana geldiği alanlarda afet sırasında ve sonrasında yapılan çalışmalarda kullanılacak kaynakların doğru ve etkin kullanılması önemlidir. Afet öncesi, sırası ve sonrasında gelişmiş teknoloji sensörlerinin etkin kullanımı; afet etkisini azaltma, tespit, müdahale ve afet bölgesini yenilemek için afet yönetimi adımlarında önemli faydalar sağlar. Bu noktada uzaktan algılama verileri, özellikle zaman içinde felaket bölgelerinde meydana gelen değişiklikleri izlemek için başvurulan kaynakların başında gelmektedir. Çalışmamızda taşkın alanları, afet bölgesine ait afet öncesi ve sonrası değişimini gösteren çok bantlı uydu görüntülerinden yararlanılarak nesne tabanlı sınıflandırma yaklaşımı kullanılarak belirlenmiş ve sınıflandırılması yapılmıştır. Uydu verilerinden tespit edilen taşkın alanları CBS ortamına aktarılarak taşkın alanın afet öncesi ve sonrasına ait analizleri yapılmıştır. Sonuçlara göre değişimlerin büyüklüğü ve önemi göz önünde bulundurularak değerlendirmeler yapılmıştır.

ANAHTAR KELimELER: Afet yönetimi, Değişim tespiti, Görüntü işleme, Nesne tabanlı sınıflandırma, Taşkın, Uzaktan algılama

\section{Analysis of Flood Areas with Object-Based Classification}

\begin{abstract}
\footnotetext{
${ }^{1}$ Harita Müh. Bölümü, Kocatepe Üniversitesi, Afyonkarahisar

*ilgili yazar / Corresponding author: abdurahmanyasinyigit@gmail.com

Modern remote sensing systems are used extensively by almost all disciplines around the world and their scope is increasing day by day. Nowadays, the possibility of evaluating the remote sensing data obtained from satellites with computer technology and image processing techniques; It was made possible by determining the current land use and temporarily determining the environmental changes. The main principle of creating land cover maps with remote sensing techniques is to classify the images of the area. The temporal changes of the terrain can be detected by processing and classifying the remote sensing data from the satellites. Correct and effective use of resources to be used during and after disasters is important in areas where earthquake events, floods, fires, landslides, and avalanches occur. Effective use of advanced technology sensors before, during and 
after disasters; It provides significant benefits in disaster management steps to mitigate, identify, respond to, and renew disaster zones. At this point, remote sensing data is one of the main sources used to monitor the changes that occur especially in disaster areas over time. In our study, flood areas were determined and classified using object-oriented approach by using multi-band satellite images showing the change before and after the disaster. The flood areas determined from the satellite data were transferred to the GIS environment and the flood area was analyzed before and after the disaster. According to the results, evaluations were made considering the magnitude and importance of the changes.

KEYWORDS: Disaster management, Change detection, Image processing, Object-based classification, Flood, Remote sensing

\section{GíRiş}

İnsan nüfusunun artması, doğanın tahribi, bilinçsiz kentleşme ve teknolojik gelişmelerin çevresel zararları sebebiyle afetlerin sıklığı ve afetlerden kaynaklanan can ve mal kaybı gün geçtikçe artmaktadır.

Afet; bir topluluğun veya toplumun işleyişini ciddi şekilde bozan topluluğun veya toplumun kendi kaynaklarını kullanarak başa çıkma yeteneğini aşan insani, maddi ve ekonomik veya çevresel kayıplara neden olan doğal ve insan kaynaklı olayların sonucudur (EMA, 2008). Afet tanımından da açık bir şekilde anlaşılacağı gibi bir olayın nasıl meydana geldiği değil olayın doğurduğu sonuçlar afet olarak nitelendirilmektedir. Afet ve Acil Durum Yönetimi (AADY) ile afetin oluşmasına sebep olan sonuçlar azaltılabilir veya aza indirilebilir (Demir vd., 2011). Kapsamlı afet yönetiminin aşamaları Şekil 1'de gösterildiği gibi, bir afet olayını takip eden ve bir sonraki afete kadar birbirini takip eden bütün aşamaları ifade eder (Koçkan, 2015).

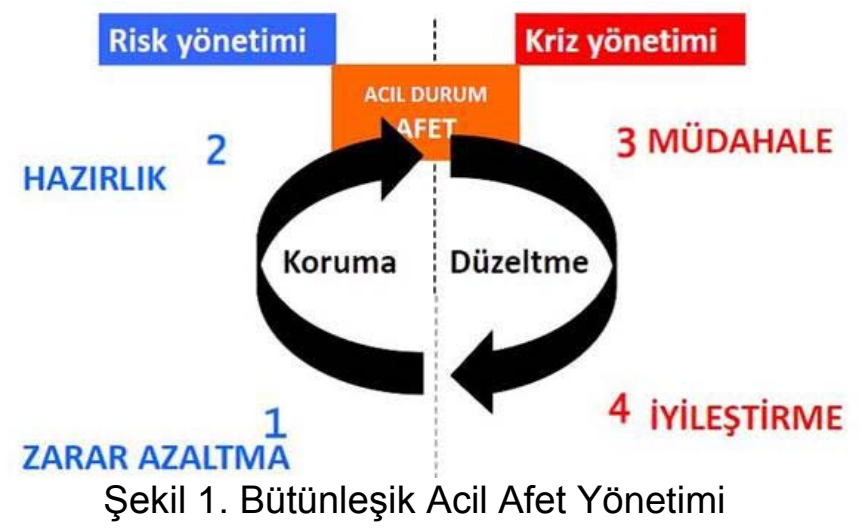

Afet Türleri; önem sıralarına göre bölgeden bölgeye, ülkeden ülkeye farklılık göstermektedir. Dünyada görülen başlıca doğal afetler, oluşum nedenlerine göre jeolojik, klimatik, biyolojik; insan kaynaklı afetler ise sosyal ve teknolojik afetler olarak gruplandırılabilir (Özey, 2004).

BM Afet Riskini Azaltma Merkezi, Afet Epidemiyolojisi Araştırma Merkezi tarafından geçtiğimiz yıl kaydedilen 281 doğal afet analizi ve Uluslararası Afet Veri Tabanı (CRED) tarafından hazırlanan raporlara dayanarak geçtiğimiz yıl dünyada 61 milyon 700 bin kişinin deprem, tsunami, taşkınlar, kuraklıklar, fırtınalar ve orman yangınları gibi doğal afetlerinden etkilendiği bildirilmiştir (Kamiloğlu, 2019). Uluslararası Kızılhaç ve Kızılay Dernekleri Federasyonu'nun (International Red Cross and Red Crescent Movement-IFRC) verilerine göre dünyada son 10 yılda yaşanan doğal afetler yaklaşık 2 milyar kişiyi etkilemiştir (IFRC, 2018). 
Geçen on yılda dünya genelinde 3 bin 750 doğal afet meydana gelmiştir. 2018 yılı dünya afet raporunda; çocuk, kadın ve erkeklerin yüzde 95'inin hava koşulları ile bağlantılı afetlerin olumsuz etkisini yaşadığı belirtildi. Dünyada 2018 yılında meydana gelen doğal afetler nedeniyle 10 bin 733 kişi hayatını kaybetöiş ve afetlerden 61 milyon 700 binden fazla kişi etkilenmiştir (Akra, 2018).

Afet Epidemiyolojisi Araştırma Merkezi tarafından doğal afetlerle ilgili hazırlanan raporda, 2000 -2017 yılları arasında ve 2018 yılında yaşanan can kayıpları ve yaşanan doğal afet türleri yayınlanmıştır (Tablo 1).

Tablo 1. 2000 -2017 ve 2018 yıllarında yaşanan can kayıpları ve yaşanan doğal afet türleri (Kamiloğlu, 2019)

\begin{tabular}{|c|c|c|}
\hline Doğal Afet Türü & $\mathbf{2 0 1 8}$ & $\mathbf{2 0 0 0 - 2 0 1 7}$ \\
\hline Kuraklık & 0 & 1.361 \\
\hline Deprem & 4.321 & 46.173 \\
\hline Aşırı Sıcak & 536 & 10.414 \\
\hline Sel & 2.859 & 5.424 \\
\hline Heyelan & 282 & 929 \\
\hline Kütle Hareketleri & 17 & 20 \\
\hline Fırtına & 1.593 & 12.722 \\
\hline $\begin{array}{c}\text { Volkanik } \\
\text { Hareketler }\end{array}$ & 878 & 31 \\
\hline Orman Yangınları & 247 & 71 \\
\hline Toplam Can Kaybı & 10.733 & 77.144 \\
\hline
\end{tabular}

Sel, dünyadaki en yaygın doğal felaketlerin başında gelmektedir. Doğal nedenlerden dolayı mal kaybının \%40'ı selden kaynaklanmakta ve bununla birlikte dünyadaki ölümlerin yarısından fazlasına da seller neden olmaktadır. Bir araştırmaya göre, Türkiye'de yaşanan felaketlerden neredeyse herkes (\%85) ilk olarak depremi akla getirmektedir. Türkiye'de her 5 kişiden 2'si; sel, dolu, fırtına, toprak kayması, kuraklık, çığ ve volkanın yıkıcı etkilerini düşünmemektedir.

Son otuz kırk yılda, taşkın olaylarının sıklığı ve yoğunluğundaki artıştan dolayı can ve mal kaybı büyük ölçüde artmıştır. Sadece son on yılda, dünyadaki sel felaketlerini telafi etmek için 250 milyar doların üzerinde para harcanmıştır (Sönmez ve Demir, 2016). Sellerin sayısı ve olumsuz etkisi artmasına rağmen alınan tedbirler neticesinde ölümlerin sayısı yıldan yıla azalmaktadır (Güney, 2017).

Risk yönetim danışmanlığı ve hasar yöneticiliğinde faaliyet gösteren uluslararası bir sigorta şirketi olan Aon'un 2019'un ilk 6 ayını kapsayan Küresel Doğal Afetler Raporuna göre 2019'un ilk yarısında gerçekleşen doğal afet kaynaklı kayıpların; 2000-2018 yılları arasındaki ortalama 94 milyar dolarlık kayba göre yüzde 22 düşüşle 73 milyar dolar olacağını öngörülmektedir. 2019'un ilk yarısında önemli ekonomik kayıplara yol açan doğal afetlerde, toplamda 3800 kişi hayatını kaybetmiştir. Rapora göre en çok ölüme yol açan doğal afetler olan tropik siklonlar ve sel baskınları, sırasıyla 1500 ve 1425 kişinin hayatını kaybetmesine neden olmuştur. Tropik siklonlar nedeniyle yaşanan can kayıplarının büyük bir bölümü Afrika'da yaşanırken sel baskınlarından kaynaklanan en büyük maddi zararlar ise Amerika kıtasından gerçekleşmiştir (Özay, 2019). 
İklim değişiklikleri ve çevresel bozulmalarla yakından ilgili olan sel felaketlerinin büyüklüğü ve sıklığı bölgeden bölgeye değişiklik göstermektedir. Taşkın felaketi büyüklüğü, sıklığı, oluşumu, can ve mal kaybı ile sosyo-ekonomik aktivitelere verdiği zararlarla en büyük küresel tehlike olarak kabul edilmektedir (Jeb ve Aggarwal, 2008).

Genel olarak dünyanın farklı yerlerinde meydana gelen taşkınlar; yağış dengesindeki değişimler ve küresel ısınma sonucu çevresel zararın yanında her yıl milyonlarca insanı etkileyen, ani ve belirli periyotlar sonucunda iklim değişikliğini ve doğal bitki örtüsündeki değişiklikleri de beraberinde getiren, yaşamı ve mülkü olumsuz yönde etkileyen bir doğal afettir. Sel ve taşkınlar birçok farklı nedenden ötürü meydana gelmektedir. Yağış şekli ve yoğunluğu, drenaj şebekesi ve geometrisi, toprak özellikleri, bitki örtüsü ve tarım alanlarının açılması, kentleşme, sanayileşme ve ulaşım gibi insan faktörleri gibi birçok doğal faktörden dolayı sel ve taşkınlar meydana gelebilmektedir (Campana ve ark., 2011; Karabulut ve ark., 2007).

Afet olaylarında yaşanan can ve mal kayıplarını en aza indirmek için afet yaşanmadan öncesinde tedbirlerin alınmasının ve halkı uyarmanın önemi kadar afet sırasında doğru ve hızlı bilgi paylaşımı ve afet sonrasında afetin meydana getirmiş olduğu zararın boyutunu belirleme ve telafi etmek için de sağlıklı kaynaklardan doğru bilgi edinmek önem arz etmektedir.

Günümüzde birçok disiplin için uzaktan algılama, güvenilir bir temel olduğu için vazgeçilmez bir kaynak haline gelmiştir. Uzaktan algılama uydu verileri sayesinde bilgiye çok kısa sürede, güvenilir ve ekonomik bir şekilde erişilebilir. Bunun sonucunda alınacak önlemler ve çalışmalar kısa sürede planlanabilir. Büyük doğal olayların uzaktan algılama yöntemleriyle izlenmesi tekrarlayan hasarların önlenmesinde ve minimum hasarla sonuçlanması adına çok önemlidir. Uzaktan algılama teknikleri, mekânsal değişiklikleri görsel şekilde sunma ve geçmiş ile şimdiki dönemleri karşılaştırmak için önemli olanaklar sağlar.

Uzaktan algılama teknikleri; arazi kullanımındaki değişiklikler, su yüzeylerindeki mekânsal değişiklikler, iklim değişiklikleri, sıcaklık ve yağış gibi iklim unsurlarındaki sapmaların periyodik olarak hesaplanması, şehir planlarının oluşturulması, nehir havzalarının izlenmesi ve doğal afetlerin etki boyutlarının belirlenmesi gibi alanlarda hızla genişleyen bir kullanım alanına sahip olmaya başladı. Uzaktan Algılama; haritacılık, şehir ve bölge planlama, doğal afetlerin izlenmesi, subilimi, jeoloji, tarım, biyoloji, çevre ile ilgili çalışmaları, meteoroloji, askeri istihbarat gibi birçok alanda sıklıkla kullanılmaktadır. Uzaktan algılama teknikleri, geniş alanları uzak mesafelerden görüntüleme, istenen miktarda veri depolama, hızlı hesaplama, sistem çıktılarının çok yönlü olması ve hesaplamak için çok zor olan verileri klasik yöntemlere göre daha kolay ve daha kısa sürede ulaşması gibi imkânlar sunar. Uzaktan algılamanın mekândaki değişimi, sürdürülebilirliğini ve değişim eğilimlerini belirleme de önemli katkıları bulunmaktadır.

Tunay ve Ateşoğlu (2004) Bartın çayını oluşturan Ulus Çayı ve Kozcağız Çayı taşkın sahalarındaki değişimlerin analizin yapmışlardır. Çalışmalarında 1992 ve 2000 yıllarına ait uydu verilerini kullanmışlardır. Her iki uydu görüntüsü değerlendirildikten sonra taşkın alanına ait değişim miktarı hektar bazlı olarak tespit edilmiştir. Ortaya çıkan sonuçlar doğrultusunda meydana gelen değişimlerin boyutu ve önemine dikkat edilerek bu konuda öneriler ele alınmıştır.

Bahadır (2013) çalışmasında Göller Yöresi'nde yer alan, Akşehir Gölü'nün uzun yıllık dönemde göl seviyesinde ve alanında meydana gelen değişimleri uzaktan algılama teknikleri kullanılarak incelemiştir. Bu çalışmada kullanılan uydu görüntüleri ele alındığında Akşehir Gölü'nün seviye değişimlerinde 1985 yılından 2005 yılına kadar ki 20 yıllık dönemde bir 
azalma tespit edilmiştir. Uydu görüntü verilerinin detaylı incelenmesi sayesinde Akşehir Gölü’nde hızlı bir şekilde alan kaybının yaşandığı belirtilmiştir. Çalışma sonunda bu denli bir alan kaybının önlenebilmesi mümkün olmadığı dile getirilmiş ve bu alan kaybının yavaşlaması anlamında bazı acil önlemlerin alınması gerekmektedir.

Uysal ve arkadaşları (2011) çalışmalarında, uzaktan algılama verilerinden yararlanarak Akşehir ve Eber göllerinin kıyı şeridi ve su seviyesi değişimlerini araştırmayı ve göl seviyelerinde düşüşün nedenlerini belirlemeyi amaçlamışlardır. Görüntü analizleri sonucunda, Akşehir ve Eber Göllerinin su yüzey alanlarının 1975 ve 2010 yılları arasında 356,929 kilometre kareden 126,88 kilometre kareye düştüğü tespit edilmiştir. Uzaktan algılama verileri sayesinde, Akşehir ve Eber Gölleri kıyılarında, su rezervlerinde meydana gelen zamansal ve mekânsal değişimler ile ikliminin göl seviyeleri ve su rezervleri üzerindeki etkisi hakkında değerli bilgiler sağlandığı belirtilmiştir. Çalışma sonunda uzaktan algılama yöntemlerinin göl izleme amacıyla daha kapsamlı olarak çeşitli projelerde başarılı bir şekilde uygulanabileceği söylenmiştir.

Uzaktan algılama, son yıllarda afet yönetiminde önemli bir teknoloji olmuştur. Afet öncesi, sırası ve sonrasında uzaktan algılama verilerinin etkin kullanımı; afet etkilerini azaltmak, tespit etmek ve müdahale etmek gibi afet yönetimi adımlarında önemli yararlar sağlamaktadır. Afetin etkisini hızlı bir şekilde incelemek afet sonrası müdahaleye önemli katkılar sunmaktadır. Bu amaçla çalışmamızda, ücretsiz olarak dijital platformda sunulan uzaktan algılama verilerinden olan uydu görüntüleri sayesinde taşkın alanlarının tespitinin hızı bir şekilde yapılabileceği gösterilmeye çalışılmıştır. Bu amaç doğrultusunda uydu görüntü verisi kullanılarak nesne tabanlı sınıflandırma yöntemi ile Mart 2019 tarihinde Amerika'da meydana gelen taşkın felaketinin analizi yapılmıştır. Taşkın alanına ait; taşkın öncesi, sırası ve sonrasındaki değişim incelenmiş ve tespit edilmiştir. Bunun için taşkın öncesi ve taşkın sonrası olmak üzere 5 farklı zamana ait uydu görüntüleri kullanılmıştır.

\section{2. ÇALIŞMA ALANI ve VERI SETI}

\section{1 Çalışma Alanı}

Çalışma alanı olarak, Mart 2019 tarihinde ABD'nin (Amerika Birleşik Devletleri) orta-batı bölgesinde bulunan Nebraska eyaletine bağlı Omaha kentinde (Şekil 2) gerçekleşen taşkın afeti bölgesi tercih edilmiştir. Şehir $41^{\circ} 15^{\prime} 6.85^{\prime \prime K}$ enlemi ve $95^{\circ} 56^{\prime} 22.92 " B$ boylamında, Missouri Nehri sahilinde konumlanmış olup bu nehre katılan "Platte Nehri" ağzının $30 \mathrm{~km}$ kuzeyindedir (Şekil 2).

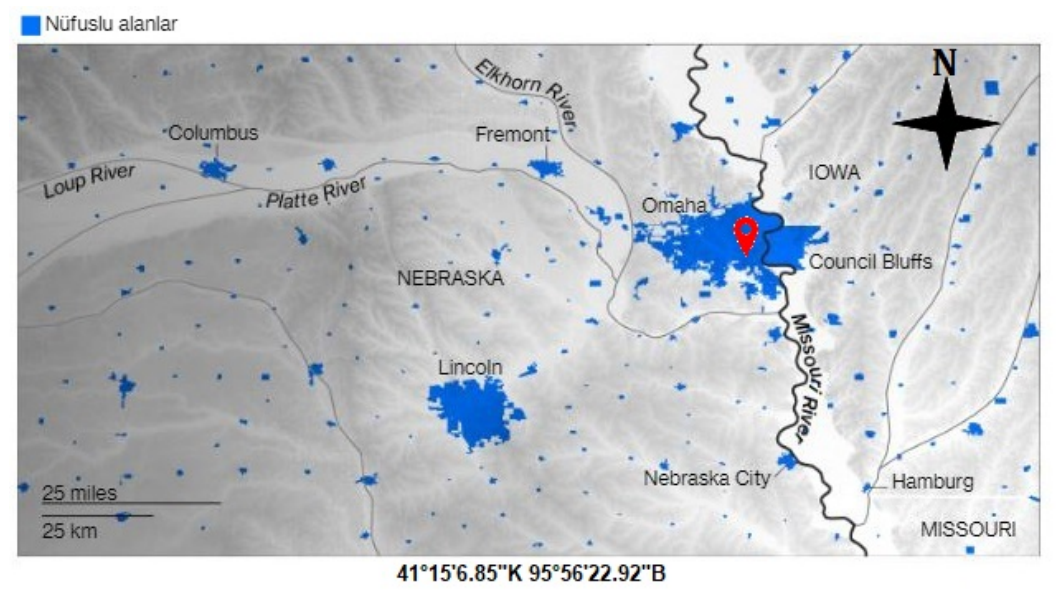

Şekil 2. Afet bölgesi konumu (Justin, 2019; United States Geological Survey/EsriUnited States Geological Survey; Esri) 
Şekil 3'te de gösterildiği üzere karların hızlı bir şekilde erimesi sonucunda nehirlerin debisi ani bir şekilde yükselmiş ve taşkın felaketi yaşanmıştır (URL-2).

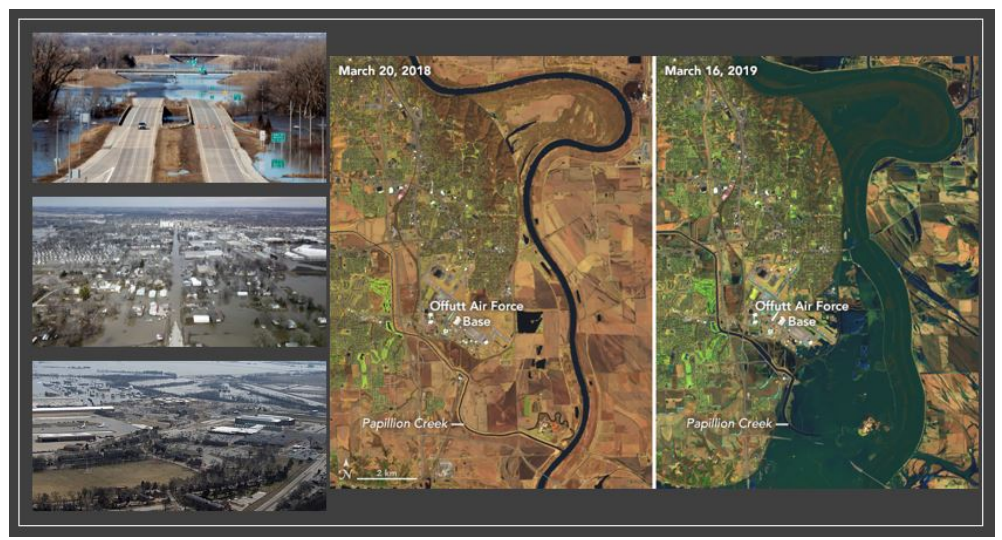

Şekil 3. Afet bölgesi ve afet bölgesine ait uydu görüntüsü (Joshua, 2019)

Afetin yaratmış olduğu maddi zarar; 1,6 milyar dolar taşınmaz, 500 milyon dolarlık hayvan kaybı, 400 milyon dolarlık tarımsal zarardır. Bu maddi zarar ABD'nin tarihi boyunca yaşamış oldu en büyük maddi hasara yol açan doğal felakettir (Ristau, 2019; Joshua, 2019)

Çalışma alanı olarak Nebraska eyaletindeki taşkın alanının seçilmesinde bu denli büyük maddi zarar olması etken olmuştur.

\subsection{Veri Seti}

Uydu sensör sistemleri ile yeryüzü hakkında çok sayıda fotografik ve dijital veri elde etmek mümkündür. Bu veriler, dünyanın kaynaklarının araştırılması, kentsel gelişim planlaması, arazi kullanımının araştırıması ve çevre kirliliğinin izlenmesi gibi uygulamalarda yaygın olarak kullanılmaktadır. Hem fotoğraf hem de tematik haritalarda ve güncelleme çalışmalarında, hız, doğruluk ve maliyet açısından uzaktan algılama görüntüleri kullanmak büyük kazanım sağlamaktadır. Uydu yüksekliğinin sinoptik görüntüsü, uydu sensörlerinin hareket hızı ve kullanılan spektral bantların sayısı nedeniyle, büyük miktarda veri üretebilmektedir (Özkan, 2000). Uydu görüntüleri ormancılıktan jeodeziye, meteorolojiden askeri uygulamalara kadar birçok alanda kullanılmaktadır. Uydu görüntülerinin insan gözünün algılayamadığı bitki hastalıkları, klorofil miktarı, su kalitesi ve su kirliliği gibi özellikleri ayırt edebilmesi birçok kolaylığı ve analiz kolaylığını da beraberinde getirmiştir (Kalkan ve Maktav, 2010).

Afet bölgesine ait 2 adet afet öncesine, 3 adet afet sonrasında olmak üzere 5 adet uydu görüntüsü Sentinel-2A (Şekil 4) uydusundan temin edilmiştir.

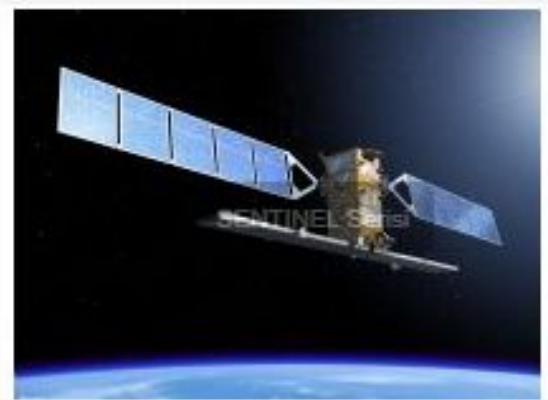

Şekil 4. Sentinel-2A uydusu (URL-3) 
Sentinel-2A uydusu kutup yörüngeli, multispektral yüksek çözünürlüklü algılayıcıya sahip bir uydu olup vejetasyon, toprak ve su kaplama alanları gibi arazi analizlerinin yapılmasını amaçlamıştır. Sentinel-2A ayrıca acil durum servisleri için de bilgi aktarımı yapabilmektedir (URL-3). Sentinel-2A'nın multispektral görüntüleri yüksek çözünürlüklü 13 banttan oluşmakta (Tablo 2) ve 3 görünür aralık ve yakın kızıl ötesi bantları için 10 metre çözünürlüğe sahipken, kırmızı kenar (Red Edge) ve kısa dalga kızılötesi (SWIR) 6 bant için 20 metre ve son olarak 3 atmosferik bant için ise 60 metre çözünürlükte veri sağlamaktadır. Uydunun bu kadar geniş aralıkta bantta veri sağlamasının yanında en büyük faydası; bu servis ile paylaşılan bütün yersel görüntülerin 5 ila 7 günde bir tekrar aynı konumdan geçerek yakın aralıklı zamansal veriler kaydetmesidir. Bitki örtüsü değişiklikleriyle ilgili yüksek çözünürlüklü hassas ve sık zaman aralıklı görüntüleri sayesinde tarım ve orman koşullarının iyileştirilmesi, arazi örtüsü değişikliklerinin izlenmesi gibi amaçlar için çok faydalı olan uydu, tüm Dünya'ya ait görüntü sağlamasıyla acil durum ve afetlerin yönetimine yardımcı olmaktadır (URL-4). Sentinel-2A uydu görüntüleri Avrupa Uzay Ajansı tarafından ücretsiz olarak dijital platformda kullanıcılarla paylaşılmaktadır.

Tablo 2. Sentinel-2 uydu görüntüleri dalga boyu aralığı ve bantlara göre çözünürlükleri (URL-

4)

\begin{tabular}{|c|c|c|c|}
\hline Band & Açıklama & $\begin{array}{c}\text { Dalga Boyu } \\
(\boldsymbol{\mu m})\end{array}$ & $\begin{array}{c}\text { Konumsal } \\
\text { Çözünürlük }(\mathbf{m})\end{array}$ \\
\hline 1 & Kıyılar ve Aerosol (Coastal/Aerosol) & $0.433-0.453$ & 60 \\
\hline 2 & Mavi (B) & $0.458-0.523$ & 10 \\
\hline 3 & Yeşil (G) & $0.543-0.578$ & 10 \\
\hline 4 & Kırmızı (R) & $0.650-0.680$ & 10 \\
\hline 5 & Vejetasyon Red Edge & $0.698-0.713$ & 20 \\
\hline 6 & Vejetasyon Red Edge & $0.733-0.748$ & 20 \\
\hline 7 & Vejetasyon Red Edge & $0.773-0.793$ & 20 \\
\hline 8 & NIR (Yakın Kızı Ötesi) & $0.785-0.900$ & 10 \\
\hline $8 A$ & Narrow NIR (Daraltılmış Yakın Kızıl Ötesi) & $0.855-0.875$ & 20 \\
\hline 9 & Su buharı (Water vapour) & $0.935-0.955$ & 60 \\
\hline 10 & SWIR - Cirrus (Kısa Dalga Kızı Ötesi) & $1.365-1.385$ & 60 \\
\hline 11 & SWIR-1 (Kısa Dalga Kızıl Ötesi-1) & $1.565-1.655$ & 20 \\
\hline 12 & SWIR-2 (Kısa Dalga Kızı Ötesi-2) & $2.100-2.280$ & 20 \\
\hline
\end{tabular}

Sentinel-2A uydusu; tarım, orman, arazi kullanımı değişikliği, arazi örtüsü değişimi. Yaprak klorofil içeriği, yaprak su içeriği, yaprak alanı indeksi gibi biyofiziksel değişkenlerin haritalandırılması; kıyı ve iç suların izlenmesi, risk ve felaket haritalaması alanlarında kullanılmaktadır (URL-5).

\section{MATERYAL ve METOT}

Hava fotoğrafları ve uydu görüntüleri dışında diğer veri toplama metotları ile gerekli bilgilerin toplanması, değerlendirilmesi ve güncellenmesi zaman alıcı bir işlem olmakla beraber daha maliyetli olmaktadır. Bu noktada gerekli verilerin toplanması ve analizi aşamasında, çok bantlı uydu görüntüleri ciddi kolaylık sağlamaktadır (Kaya ve Polat, 2019). Hava fotoğrafları ve uydu görüntülerinde bulunan bilgiler, uzun zamandır geleneksel metotlarla ve operatörler tarafından manuel bir şekilde tespit edilmektedir. Bu tespitlerin otomatik olarak yapılması proje sürecinin hızını arttırmakta ve harcanan masrafların azalmasına katkı sağlamaktadır. 
Uydu görüntülerinden taşkın alanların tespiti çalışmasında yöntem olarak nesne tabanlı sınıflandırma yöntemi tercih edilmiştir.

\section{NESNE TABANLI SINIFLANDIRMA}

Uzaktan algılama teknikleriyle arazi örtüsü haritaları oluşturmanın ana prensibi alana ait görüntülerin sınıflandırılmasıdır. Uydulardan elde edilen uzaktan algılama verilerinin işlenmesi ve sınıflandırılması ile arazilerin zamansal olarak değişimleri belirlenebilmektedir. Sınıflandırma işleminde temel amaç birbirine göre jeoreferanslanmış birden çok görüntü veya bandın bir arada analiz edilerek bu görüntülerdeki benzer istatistiki özelliklere sahip olanlarının gruplar halinde bir araya gelerek sınıflar oluşturulmasıdır (Geçen ve Sarp, 2007). Sınıflandırma çalışmalarında en çok piksel tabanlı ve nesne tabanlı yaklaşımlar kullanılmaktadır.

Geleneksel piksel tabanlı sınıflandırma yöntemi pikselin gri değerine bağlı olarak detayların çıkarımını gerçekleştirir. Bu sebepten dolayı yalnızca spektral bilgi sınıflandırma aşamasında etkin olarak yararlanılır. Bu ve bunun gibi sınırlamaları ortadan kaldırmak için nesne-tabanlı görüntü yaklaşımı tercih edilir. Nesne tabanlı yaklaşımda spektral değerler, şekil, doku ve yoğunluk gibi farklı obje özelliklerinin geniş spektrumunun tamamlanmasını imkân kılan bulanık mantığa (fuzzy logic) dayanmaktadır. Nesne tabanlı görüntü analizinin temel işlem birimi, alışılagelmiş görüntü işleme yöntemlerinin tersine tekil piksel değil, görüntü segmentleri veya nesneleridir. Burada sınıflandırma işlemi görüntü nesneleri üzerinden yapılır. Nesne tabanlı yaklaşıma bir sebep çoğu görüntü analizi uygulamasından beklenen sonucun, gerçek dünya nesnelerinin, gerçek sınıflandırma ve gerçek şekillerinde olmasıdır. Bu beklenti alışılagelmiş piksel tabanlı yaklaşımlarla sağlanamaz (Hofmann, 2001).

Ayrıca obje tabanlı sınıflandırma yöntemi piksel tabanlı sınıflandırma yönteminden farklı olarak bulanık mantık sınıflandırmasına olanak sağlar. Bu durumda her bir obje birden fazla sınıf üyeliğine sahip olabilir. Sınıf üyelikleri 0 ile 1 arasında değişkenlik gösteren bir rakam ile ifade edilir. Bu değer ölçeğinde 1 değeri pikselin o sınıfa ait tam üyeliğini temsil ederken, 0 değeri hiçbir üyeliğinin olmadığını göstermektedir. 0 ile 1 değerleri arasında değerler ise büyüklükleri oranında üyeliğin olacağını gösterir (Boyacı, 2012). Nesne tabanlı yöntemin tercih edilmesindeki bir başka sebep ise çoğu görüntü analizi uygulamasında beklenen sonuç, objelerin gerçek sınıfa atanması ve gerçek şekillerinde olmasıdır. Bu beklenti alışılagelmiş piksel tabanlı yaklaşımlarla sağlanamaz (Hofmann, 2001).

Nesne-tabanlı yaklaşım; yapıyı, dokuları ve spektral bilgileri dikkate alır. Bu sınıflandırma adımı; komşu piksellerin, sınıflandırmanın bir sonraki adımında düşünülebilecek anlamlı bölgelere dönüştürülmesiyle başlar. Bu tür segmentasyon ve topoloji oluşumları çözünürlüğe ve aynı zamanda nesnelerin ölçeğine göre ayarlanmalıdır. Bu yöntemle, sadece bireysel pikseller sınıflandırılmamakta aynı zamanda önceki bölütleme basamağı sırasında homojen görüntü nesneleri oluşturulmaktadır. $\mathrm{Bu}$ bölütleme farklı çözünürlüklerde gerçekleştirilebilirken, nesne kategorilerinin katmanlarını ayırt etmeyi de sağlar. Ayrıca piksel tabanlı sınıflandırma sadece piksellerin istatistiksel analizine dayanırken nesne tabanlı yaklaşım ise pikselleri segmentasyon aşamasında gruplandırarak bu segmentlerin renk, sıklık ve komşuluk gibi birçok özelliğini kullandığı için tematik sınıf için daha anlamlı ve olumlu sonuçlar vermektedir. Aynı zamanda nesne tabanlı sınıflandırma işlemi, kullandığı karar seti (ruleset) ya da fuzzy logic algoritmaları ile devamlı şekilde güncellenebilir bir yapıya sahiptir. En çok kullanılan nesne tabanlı görüntü analizi yazılımı olan Definiens eCognition yazıımı sahip olduğu en yakın komşuluk (nearest neighbour) sınıflandırma yöntemi ile de piksel tabanlı yaklaşıma benzer bir yaklaşım sunmakta ve aynı anlamlı sonuçları daha pratik bir şekilde vermektedir (Kalkan ve Maktav, 2010). Çalışma da Nesne 
tabanlı yaklaşım ile taşkın alanlarının belirlenmesi işlemi Definiens eCognition yazılımında gerçekleşmiştir.

\section{UYGULUMA}

Yapılan çalışmanın iş akış şeması Şekil 5'te gösterilmiştir.

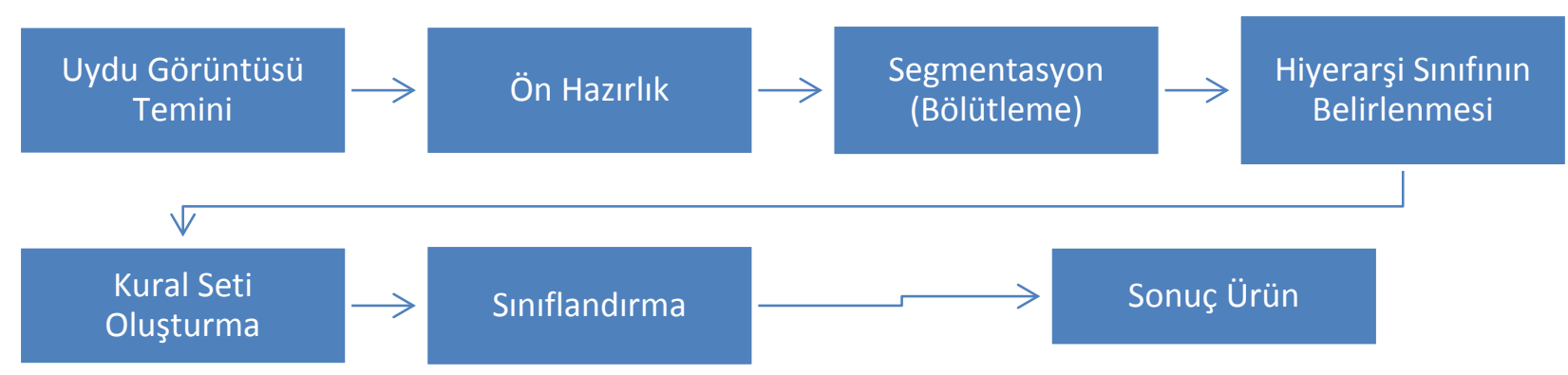

Şekil 5. İş akış şeması

\section{1 Ön Hazırlık}

Taşkın alanına ait; 2 adet taşkın öncesi (14.06.2018-05.01.2019) ve 3 adet taşkın sonrası (26.03.2019-21.03.2019-31.03.2019) olmak üzere toplam 5 adet uydu görüntüsü kullanılmıştır. Afet alanına ait 5 adet Sentinel-2A uydu görüntüsü dijital platformda ücretsiz olarak temin edilmiştir. Daha sonra 13 bantlı uydu görüntülerinden, Sentinel Application Platform (SNAP) yazılımı ile Tablo 2'de görülen Mavi (bant 2), Yeşil (bant 3), Kırmızı (bant 4) ve Yakın Kızıl Ötesi (bant 8) bantlar olmak üzere 4 bantlı uydu görüntüleri hazırlanmıştır. SNAP yazılımında ön hazırlık işlemi tamamlanan uydu görüntüleri Şekil 6'da verilmiştir.

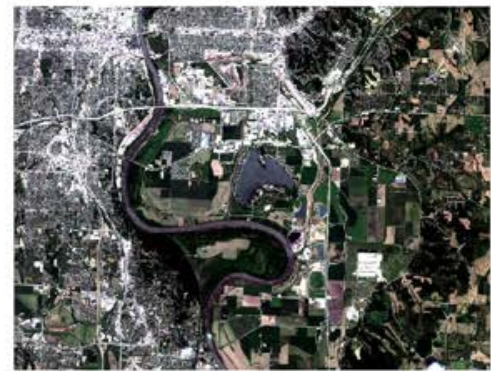

14.06.2018

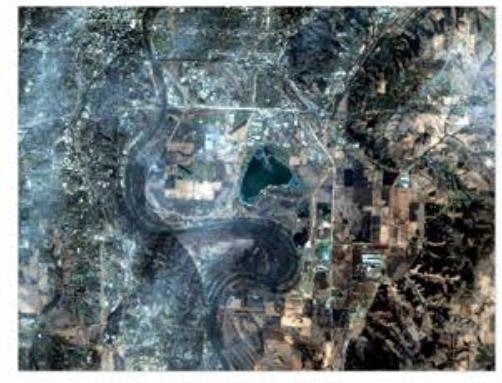

05.01.2019

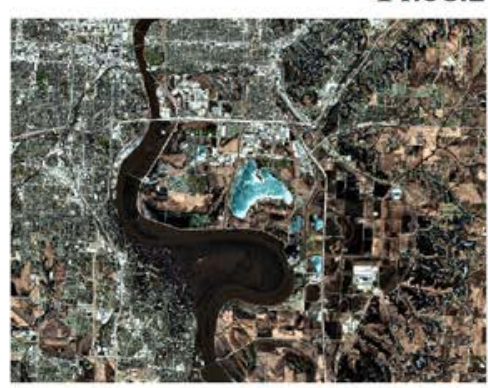

16.03.2019

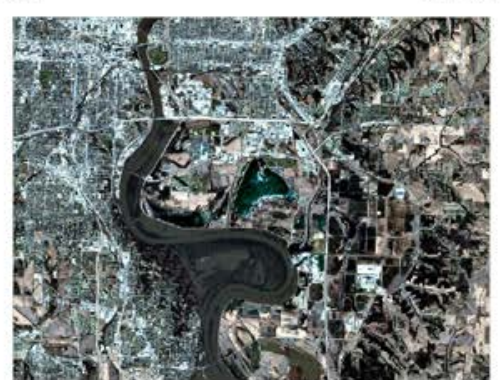

21.03.2019

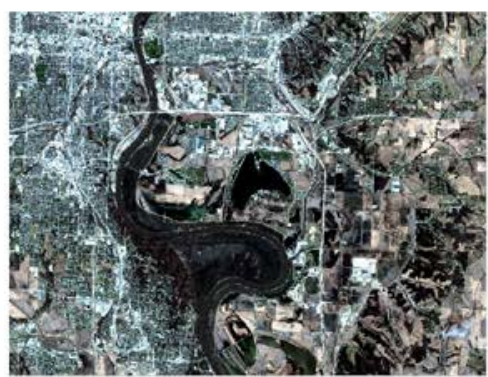

31.03.2019

Şekil 6. Sentinel 2A uydu görüntüsü 2,3,4 (Mavi, Yeşil, Kırmızı) bant birleşimi 
İstenilen bantlarda hazırlanan uydu görüntüleri, su kaplı alanların tespiti yapılmak üzere Definiens eCognition yazılımına aktarılmıştır. Definiens eCognition yazılımında detay tespiti çalışmaları segmentasyon ve sınıflandırma adımlarından oluşmaktadır.

\subsection{Segmentasyon İşlemi}

Nesne tabanlı sınıflandırma yönteminde en önemli ve ilk aşama segmentasyon aşamasıdır. Segmentasyon, benzer spektral özelliklere sahip pikselleri gruplandırma ve görüntü nesneleri oluşturma işlemidir. Segmentasyonun (bölütlemenin) amacı; görüntüyü birbirinden farklı alt bölümlere ayırmak ve görüntüden anlamlı nesneler oluşturmaktır (Baatz ve Schape, 2000). Aynı zamanda, bölütlemenin hedefleri arasında, çoğu durumda belirli bir görev için bir görüntüde istenen nesneleri otomatik olarak çıkarmak mümkündür.

Segmentasyon işlemi, yukarıdan-aşağıya (topdown) ve aşağıdan-yukarıya (bottom-up) olmak üzere iki farklı yöntem olarak işlemektedir (Definiens, 2012). Aşağıdan yukarıya strateji için kullanılan en önemli yöntem "Çoklu Çözünürlüklü Segmentasyon (Multiresolution Segmentation)" yöntemidir (Benz vd., 2004). Çoklu çözünürlüklü segmentasyon algoritmasında parametreler kullanıcı tarafından belirlenir. Bu parametreler ölçek, renk/şekil ve yumuşaklık/yoğunluk parametreleridir. Parametreler mümkün mertebe gerçeğe en yakın değerde girilmelidir. Girilen 3 parametre içinde en önemlisi ölçek parametresidir. Yumuşaklık/yoğunluk ve Renk/şekil parametreleri birbirini 1'e tamamlar. Çalışmada kullanılan segmentasyon parametreleri Tablo 3'te verilmiştir.

Tablo 3. Segmentasyon aşamasında girilen parametre ve değerleri

\begin{tabular}{cc}
\hline Parametre & Değer \\
\hline Scale & 200 \\
Shape & 0.5 \\
Compactness & 0.5 \\
\hline
\end{tabular}

Segmentasyon aşamasında Tablo 3'te girilen bu 3 parametre farklı kriterlerde test edilmiş olup 5 uydu görüntüsüne de aynı değerler uygulanmıştır. Seçilen parametreler sonucu oluşan segmentasyon sonucu Şekil 7'de gösterilmiştir. 


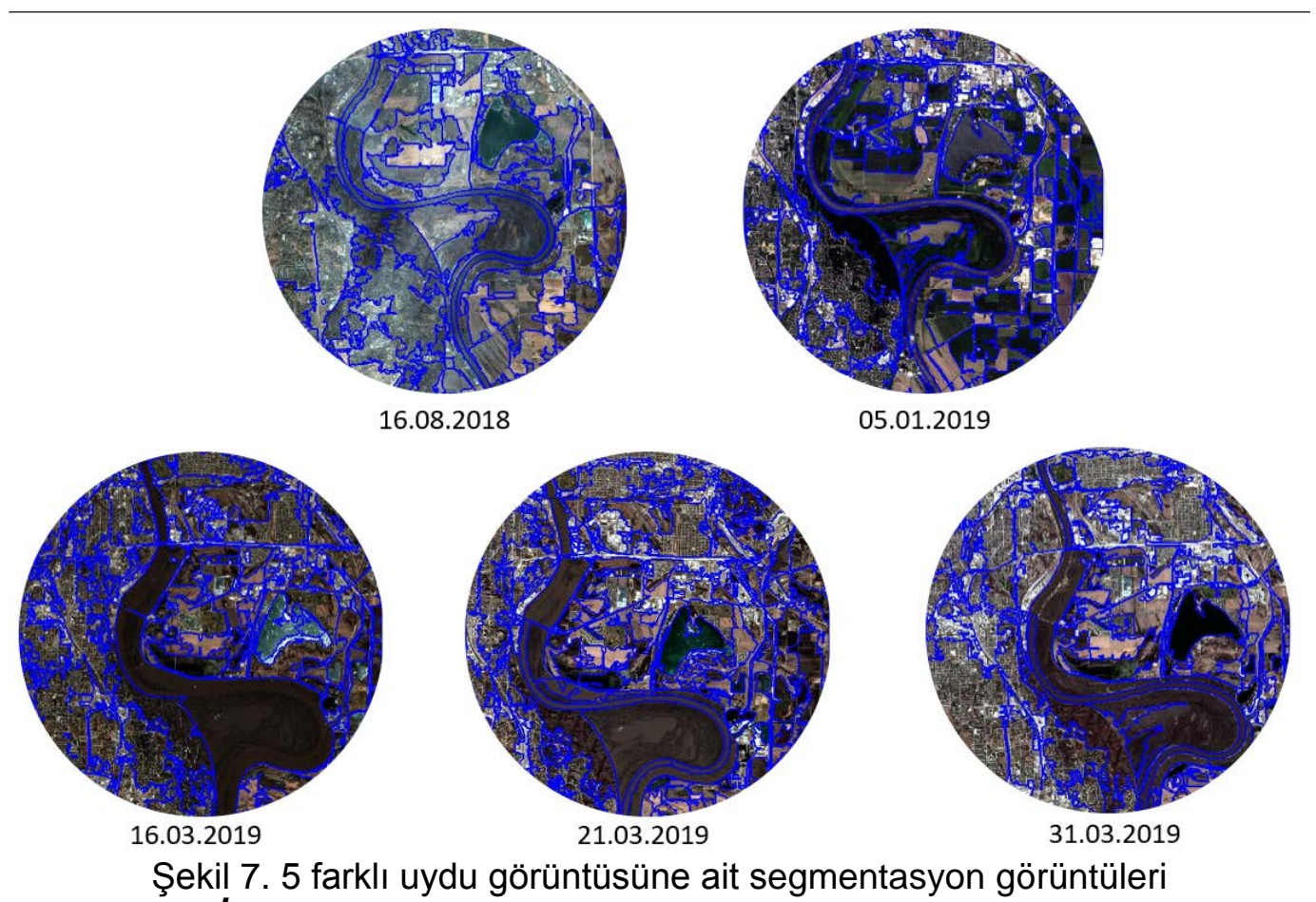

\subsection{Sınıflandırma Işsımi}

Segmentasyondan sonra sınıflandırma işlemi yapılmıştır. Sel alanlarını sınıflandırmak için eşitlik 1'deki denklemde gösterilen Normalize Edilmiş Fark Su İndeksi (NDWI: Normalized Difference Water Index) (Gao, 1996) kullanılmıştır.

$$
N D W I=\frac{\text { Green }-N I R}{\text { Green }+ \text { NIR }}
$$

Sınıflandırma aşamasında ilk olarak taşkın olan alanlara ait değerler belirlenmiş (Şekil 8) ve taşkın sınıfına atamaları yapılmıştır.
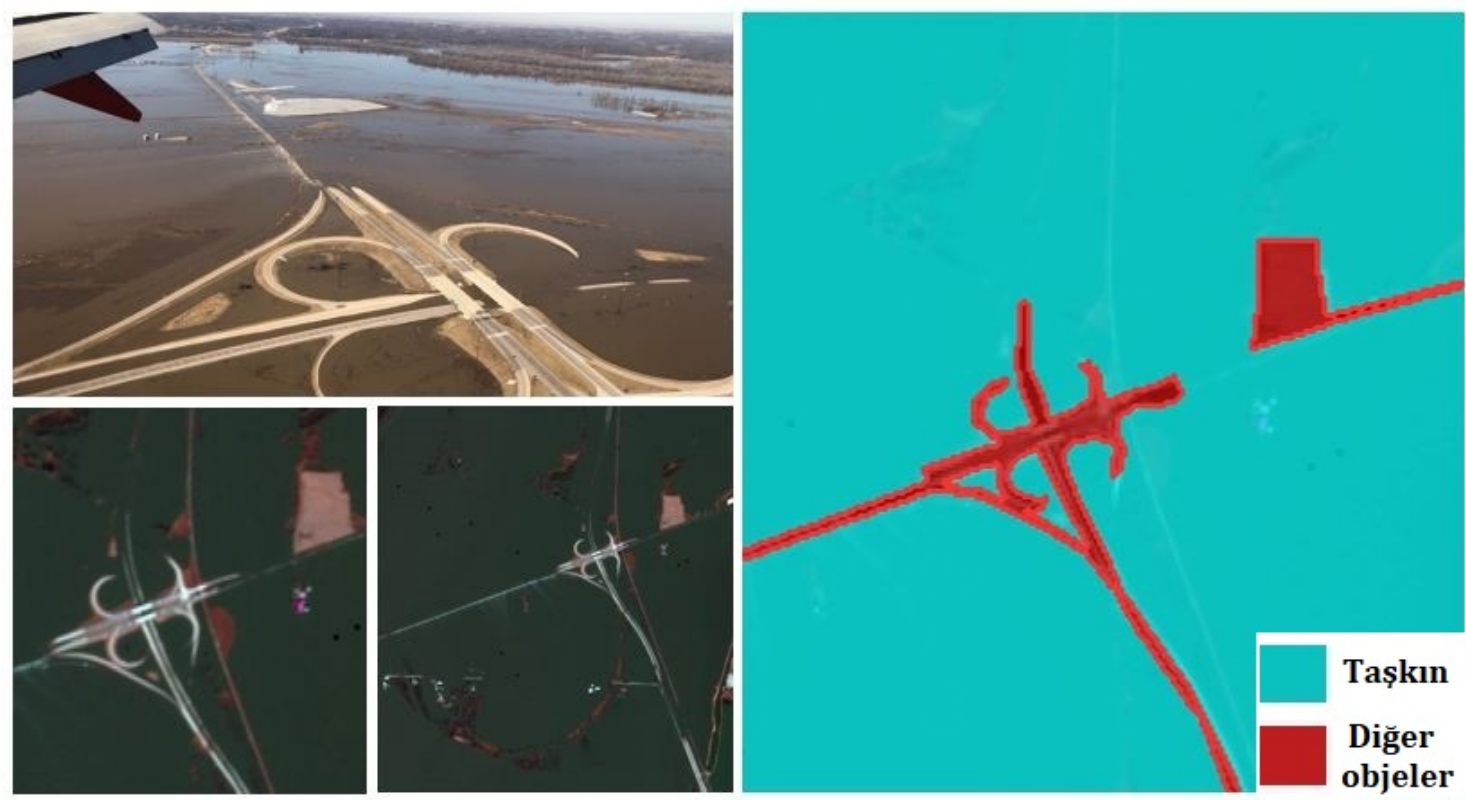

Şekil 8. Örnek obje tespiti 
Daha sonra bu sınıfa ait olmayan nesnelere ait özellikler belirlenerek taşkın sınıfından ayıklanması suretiyle taşkın alanları tespit edilmiştir. Taşkın alanları tespit edildikten sonra birleştirme (merge) işlemi ve sınır düzeltme (border reshape) işlemleri uygulanmıştır. Sınıflandırma işlemi sırasında yapılan sınıf atamaları Tablo 4'te verilmiştir.

Tablo 4. Sınıf isimleri ve kullanılan renkler

\begin{tabular}{cc}
\hline Sınıf & Renk \\
\hline Taşkın & Turkuaz \\
Diğer Objeler & Kırmızı \\
\hline
\end{tabular}

Sınılandırma işlemi sonrasında 2 adet afet öncesine ait, 3 adet afet sonrasına ait uydu görüntülerindeki nehirler ve taşkın alanları tespit edilmiş ve değerlendirilmesi yapılmıştır (Şekil 9,10 ve 11).

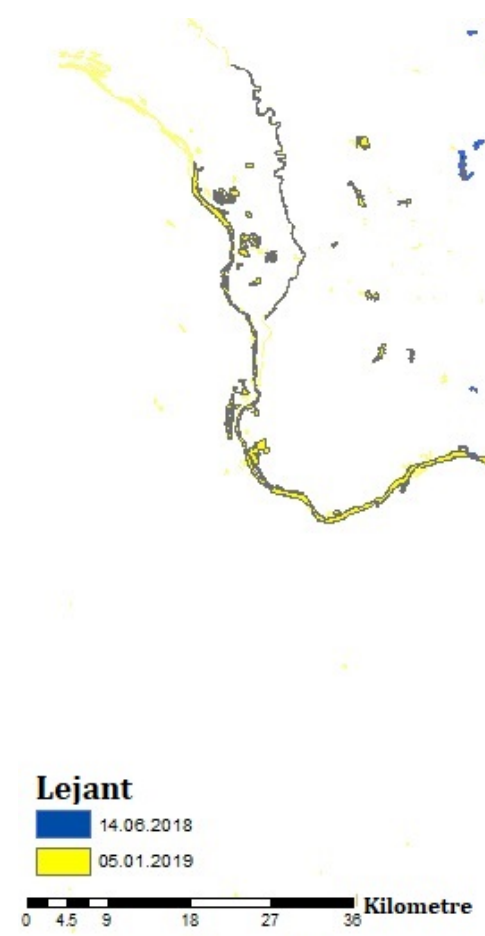

(A)

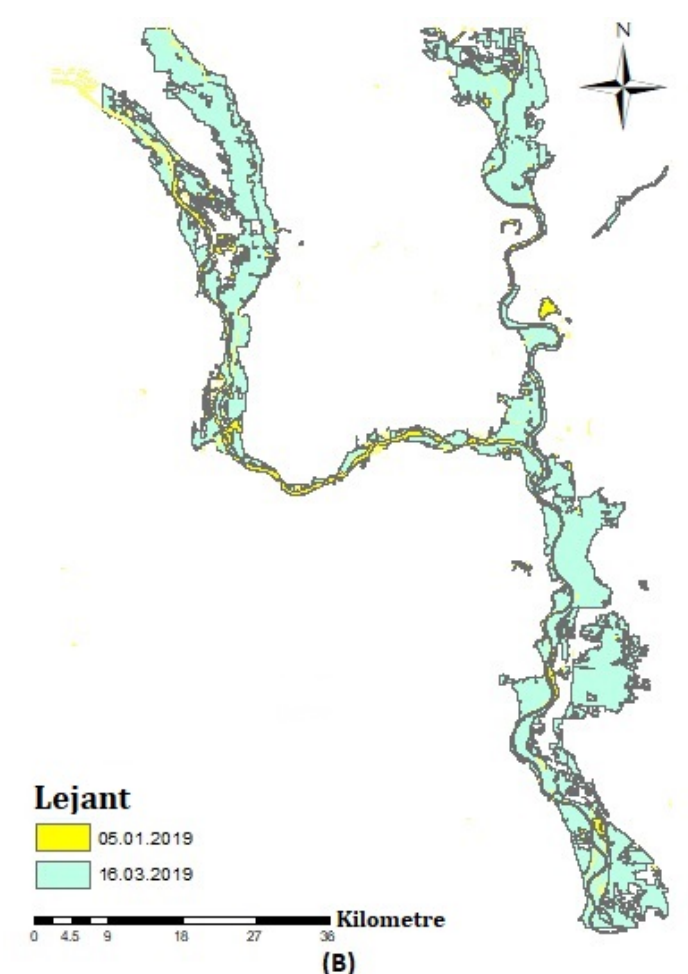

(B)

Şekil 9. 14.06.2018 - 05.01.2019 (A) / 05.01.2019 - 16.03.2019 (B) taşkın alanlarının karşılaştırıması 


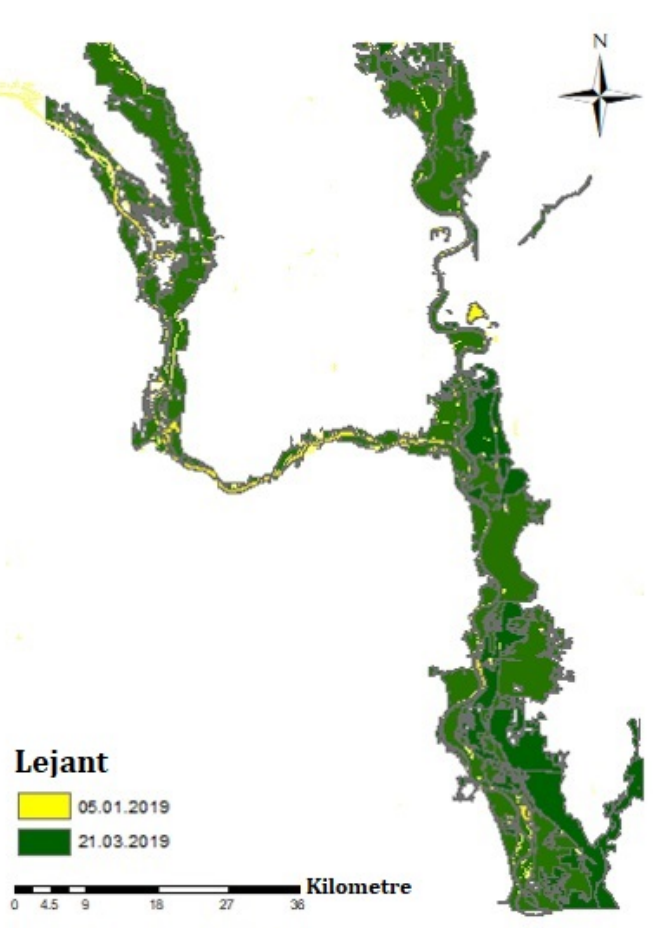

(A)

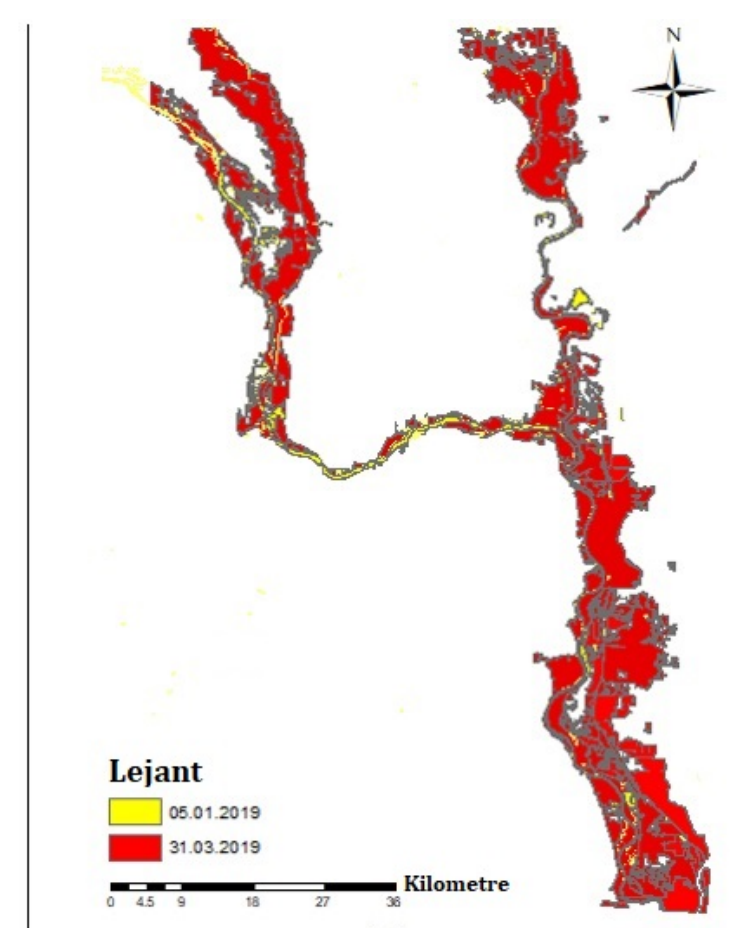

(B)

Şekil 10. 05.01.2019 - 21.03.2019 (A) / 21.03.2019 - 31.03.2019 (B) taşkın alanlarının karşılaştırıması
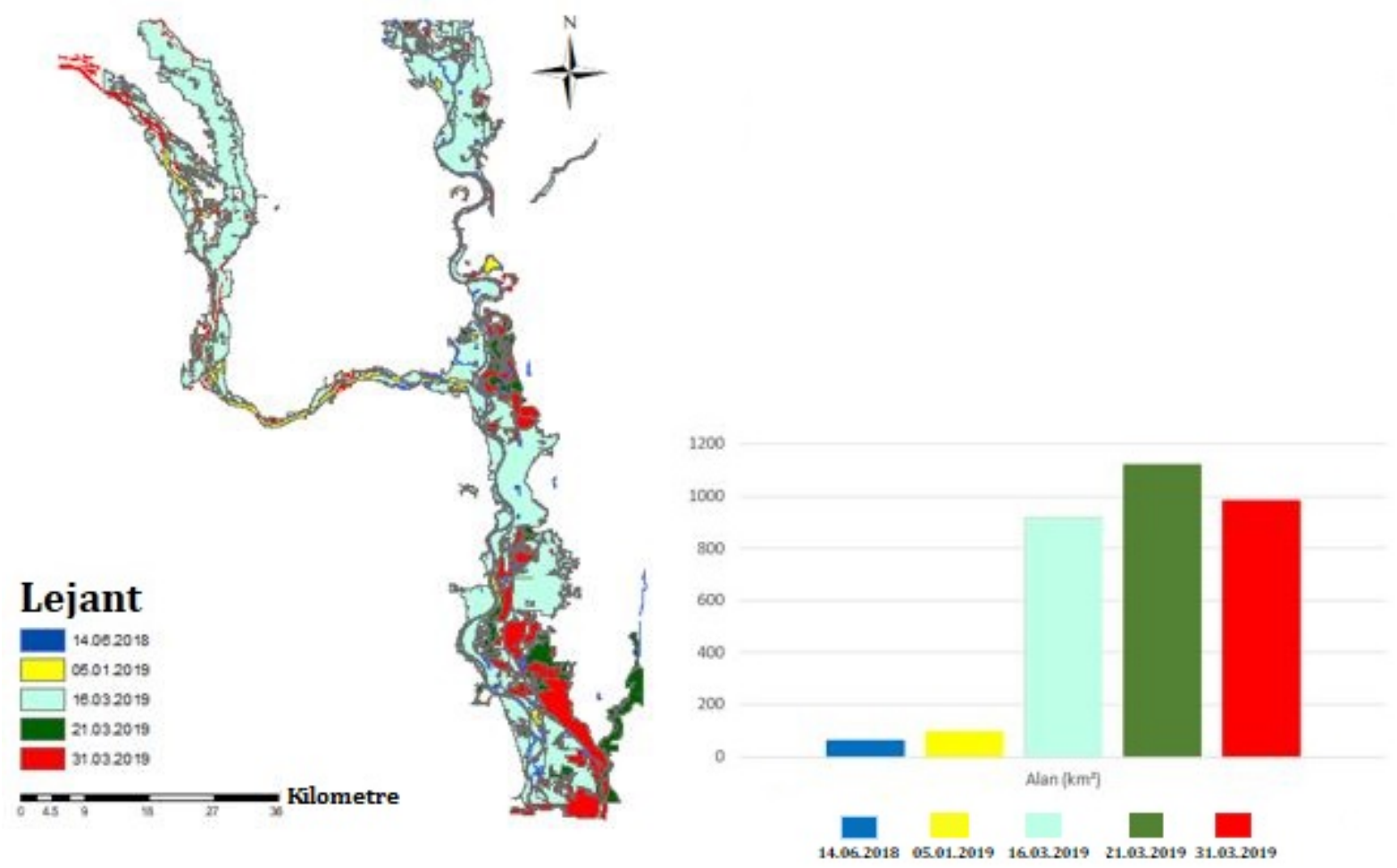

Şekil 11. Sel alanlarının sınıflandırılması ve alan bazlı karşılaştırılması 


\section{SONUÇLAR}

Ortofotolardan ve yüksek çözünürlüklü uydu görüntülerinden manuel olarak detay çıkarımı çalışmaları fazla zaman almaktadır. Sınıflandırma işleminin otomatik olarak yapılması operatör tarafından yapılmasına göre daha hızlı olmaktadır. Yüksek çözünürlüklü görüntülerden ve ortofotolardan çok fazla bilgiye erişim sağlanabilir ve çıkartımı istenen objeler detaylı bir şekilde belirlenebilir. Ayrıca segmentasyon aşamasında; spektrum, şekil, doku, gölge, bağlam, mekânsal konum dahil olmak üzere nesnenin çoklu özelliğinin kullanılması bu yöntemin avantajlarının başında gelmektedir.

Nesne tabanlı sınıflandırma yazılımı olan Definiens eCognition ile yapılan sınıflandırma süreci daha hızlı ve güncellenebilir bir şekilde gerçekleşmektedir. Ayrıca yapılan yanlışlar ya da yanlış sınıf atamaları hızlı bir şekilde manuel olarak ya da yeni sınıf atamaları yapılarak düzeltilebilir. Sınıflandırma sonucu vektör formata çevrilerek coğrafi bilgi sistemleri ile entegre edilebilir.

Çalışmamızda Sentinel-2A uydusundan elde edilen görüntülerden taşkın alanları nesne tabanlı sınıflandırma yöntemi ile belirlenmiştir. Şekil 11'de gösterildiği üzere; sınıflandırma ve detay çıkarımı sonucunda taşkın öncesi 14.06 .2018 tarihinde $63,258 \mathrm{~km}^{2}$ ve 05.01 .2019 tarihinde $101,114 \mathrm{~km}^{2}$ 'lik alan su ile kaplı görülmektedir. Taşkın sonrasına ait 16.03.2019 tarihinde $922,777 \mathrm{~km}^{2}, 21.03 .2019$ tarihinde $1124,893 \mathrm{~km}^{2}$ ve 31.03 .2019 tarihinde 984,56 $\mathrm{km}^{2}$ 'lik alanın sel suları ile kaplı olduğu tespit edilmiştir. Çalışma sonucunda değişiklik izleme çalışmalarında kullanılan Sentinel-2A uydu verilerinin etkin bir kaynak olduğu tespit edildi. $\mathrm{Bu}$ çalışmada, dünyadaki bu ve benzeri doğal olayların neden olduğu zararları ve bu zararlardan kaynaklanan değişiklikleri hassas olarak uydu teknolojisi kullanarak belirleme çalışmalarında kullanılabileceği gösterilmiştir. 


\section{KAYNAKLAR}

Akra. (2018). Doğal Afetler 10 Yılda 2 Milyar Kişiyi Etkiledi. Erişim adresi: https://www.akradyo.net/3972142272,85011,9,Dogal-afetler-10-yilda-2-milyar-kisiyietkiledi.aspx

Baatz M. Ve Schape A. (2000). Multi Resolution Segmentation: An Optimization Approach For High Quality Multi Scale İmage Segmentation. Proceedings of Twelfth Angewandte Geographische Informations verarbeitung'in İçinde, (J. Strobl, T. Blaschke, G. Griesebner Ed.), Wichmann-Verlag, Heidelberg, ss.12-23.

Bahadır, M. (2013). Akşehir Gölü’nde Alansal Değişimlerin Uzaktan Algılama Teknikleri ile Belirlenmesi. Marmara Coğrafya Dergisi Sayı: 28, Temmuz-2013, S. 246-275- İstanbulIssn:1303-2429 E-Issn 2147-7825. Erişim Adresi: http://www.marmaracografya.com

Benz U.C., Hofmann P., Willhauck G., Lingenfelder I. ve Heynen M. (2004). Multi-Resolution Object-Oriented Fuzzy Analysis Of Remote Sensing Data For GIS- Ready İnformation, ISPRS Journal of Photogramemetry and Remote Sensing, 58 (3-4), 239-258

Campana, Nestor A. ve Carlos E.M. Tucci. (2001). Predicting Floods From Urban Development Scnearios: Case Study Of The Diluvio Basin, Porto Alerge, Brazil. Urban Water, no.3

D. N. Jeb, ve P. Aggarwal. (2008). Flood Inundation Hazard Modelling Of The River Kaduna Using Remote Sensing And Geographic Information Systems. Journal of Applied Sciences Research, Vol. 4, No.12, pp.1822-1833, 2008.

Definiens. (2012). Definiens Developer XD 2.0.4. Reference Book, Definiens AG, München, Germany. $\quad$ Erişim adresi: https://www.imperial.ac.uk/media/imperialcollege/medicine/facilities/film/Definiens-Developer-Reference-Book-XD-2.0.4.pdf Erişim tarihi: (23.09.2019).

Demir, E., Yomralıoğlu, T. ve Aydınoğlu, Ç. (2011). Afet-Acil Durum Yönetimine Yönelik Coğrafi Veri Modelinin Tasarlanması: Yangın Örneği. TMMOB Harita ve Kadastro Mühendisleri Odası 13. Türkiye Harita Bilimsel ve Teknik Kurultayı, 18-22 Nisan 2011, Ankara, Türkiye.

Düzgün, Ş. (2010). Uzaktan Algılamaya Giriş. [PDF belgesi]. Erişim adresi: http://www.ktu.edu.tr/dosyalar/ormanamenajmani_3fc8b.pdf

EMA. (2008). Risk Analysis of Technological Systems Application Guide, Standards Australia, Emergency Management in Australia, Homebush.

Gao, B.-C. (1996). NDWI - A normalized difference water index for remote sensing of vegetation liquid water from space. Remote Sensing of Environment 58: 257-266.

Geçen R. ve Sarp G. (2007). Yüksek Ve Düşük Çözünürlüklü Uydu Görüntülerinden Yolların Tayini. TMMOB Harita ve Kadastro Mühendisleri Odası Ulusal Coğrafi Bilgi Sistemleri Kongresi, 30 Ekim -02 Kasım 2007, KTÜ, Trabzon

Güney, H. Naim. (2017). CUMHURIYYET Dönemindemordu'da Meydana Gelen Doğal Afetler (1919-2016). Kültür ve Sosyal İşler Dairesi Başkanlığı Kültür Yayınları - 18. 
Hofmann, P. (2001). Detecting Urban Features From IKONOS Data Using an ObjectOriented Approach. First Annual Conference of the Remote Sensing \& Photogrammetry Society 12-14 September 2001, 28-33.

IFRC. (2018). Erişim Adresi: http://www.redcross.org.cy/easyconsole.cfm/id/178/lang/en Erişim Tarihi: 25.11.2019

Joshua S. (2019). NASA Dünya Gözlemevi, ABD Jeolojik Araştırmaları'ndan Landsat verileri. Erişim adresi: https://earthobservatory.nasa.gov/images/144691/historic-floodsinundate-nebraska Erişim tarihi: 11.10.2019

Justin F. (2019, 28 Nisan). The Missouri River Is Just Going to Keep On Flooding. Bloomberg Opinion. Erişim: April 28, 2019. Erişim adresi: https://www.bloomberg.com/opinion/articles/2019-04-28/missouri-river-floods-are-just-goingto-keep-on-happening

Kalkan, K. ve Maktav, D. (2010). Nesne Tabanlı ve Piksel Tabanlı Sınıflandırma Yöntemlerinin Karşılaştırılması (IKONOS Örneği). III. Uzaktan Algılama ve Coğrafi Bilgi Sistemleri Sempozyumu Ocak 2010.

Kamiloğlu Can. (2019). Doğal Afetlerin Ürkütücü Tablosu. Erişim: 11.10.2019. Erişim adresi: https://www.amerikaninsesi.com/a/dogal-afetler-10binden-fazla-kisi-yasaminiyitirdi/4757679.html

Karabulut, M. Ersin K., Sandal K. ve Gürbüz M. (2007). Mersin Sel Felaketleri: Meteorolojik ve Hidrolik Açıdan Bir İnceleme. KSÜ Fen ve Mühendislik Dergisi. 10 no.120 Kasım - 9 Aralık

Kaya, Y. ve Polat, N. (2019). Bitki İndeksi Kullanarak Buğday Bitkisinin Fenolojik Evrelerinin İncelenmesi. Türkiye Ulusal Fotogrametri ve Uzaktan Algılama Birliği VII. Teknik Sempozyumu (TUFUAB'2019), 25-27 Nisan 2019, Aksaray Üniversitesi, Aksaray/Türkiye.

Koçkan, Ç. (2015). Doğal Afet Risk Yönetimi. 3. Türkiye Deprem Mühendisliği ve Sismoloji Konferansı, 14-16 Ekim 2015, Dokuz Eylül Üniversiesi, İzmir, Türkiye.

KTÜ, Fotogrametri ders sunumu. [PDF belgesi]. Erişim adresi: http://www.ktu.edu.tr/dosyalar/ormanamenajmani_137d4.pdf

Ozey, R. (2004). Afetler Coğrafyası, Aktif Press, Istanbul.

Özay, Ferhan. (2019). Doğal afetlerin yarıyıl bilançosu 73 milyar dolar. Yayınlanma Tarihi: Ağustos 06, 2019. Erişim adresi: https://www.sigortamedya.com.tr/dogal-afetlerin-yariyilbilancosu-73-milyar-dolar/ Erişim tarihi: 11.10.2019

Ristau, R. (2019, 19 Mart). Floodwaters receding in Nebraska, but long and costly recovery lies ahead. Winston-Salem Journal. Retrieved March 19, 2019-via Omaha World-Herald. Erişim adresi: https://www.omaha.com/news/nebraska/floodwaters-receding-in-nebraskabut-long-and-costly-recovery-lies/article 4b4778d5-f566-517f-a751-d09eb75020a1.html

Sönmez Osman ve Demir Fatma. (2016). Ağva ilçe merkezine ait taşkın yayılım haritalarının ve mevcut binaların taşkın su seviyelerinin tespiti. Sakarya Üniversitesi Fen Bilimleri Enstitüsü Dergisi, 21(2), 2017, 105-112 
Tunay, M. ve Ateşoğlu, A. (2004). Bartın İli Taşkın Sahalarındaki Değişimin Uzaktan Algılama Verileriyle İncelenmesi. Süleyman Demirel Üniversitesi Orman Fakültesi Dergisi, Seri: A, Sayı: 2, Yıl: 2004, ISSN: 1302-7085, Sayfa: 60-72

United States Geological Survey; Esri. Erişim adresi: https://www.usgs.gov/products/dataand-tools/gis-data

Uysal, M., Erdoğan, S. ve Yıldırım, Ü. (2011). Changes in the Coastline and Water Level of the Akşehir and Eber Lakes Between 1975 and 2010, Hydrography and the Environment, Bridging the Gap Between Cultures Marrakech, Morocco, S. 1-18.

URL-1. Erişim adresi: https://www.satimagingcorp.com/satellite-sensors/other-satellitesensors/sentinel-2a/ Erişim tarihi: 11.10.2019

URL-2.

Erişim

adresi: https://www.wikiwand.com/en/2019 Midwestern U.S. floods\#/overview Erişim tarihi: 11.10 .2019

URL-3. Erişim adresi: http://www.nik.com.tr/content sistem uydu.asp?id=64 Erişim tarihi: 11.10.2019

URL-4. Erişim adresi: https://blog.esriturkey.com.tr/2019/02/25/sentinel-2-uydugoruntuleriyle-esri-sentinel-2-explorer-web-uygulamasi-araciligiyla-calismak/ Erişim tarihi: 11.10 .2019

URL-5. Erişim adresi: https://www.satimagingcorp.com/satellite-sensors/other-satellitesensors/sentinel-2a/ Erişim tarihi: 11.10.2019 